\title{
BOND RUPTURE MECHANISMS IN VITREOUS SYSTEMS
}

\author{
W. C. Levengood*
}

\author{
ABST RACT
}

\begin{abstract}
An experimental comparison was made between the breaking strength of fresh cleavage surfaces on various glasses and surface flaw parameters. A direct relationship was found between the product $\mathrm{N}_{\mathrm{b}}$ of flaw length and number and the mean pressure to produce breakage in localized areas. This relationship was attributed to surface energy being utilized in flaw creation. A theory is advanced that a localized force causes a part of the mechanical stress to be relieved by flaw surface energy. producing a confined region of plastic deformation. Flaw formation in fused silica was observed to be less extensive and, as a consequence, the structure supported less localized force than commercial glasses before fracturing. The fused quartz structure was modified by adding sodium and calcium oxides; these three component glasses also disclosed the direct relation between $\mathrm{N}_{b}$ and the breaking force. By employing a dynamic indenter tool, quantitative flaw formation in systems such as fused and crystalline quartz is compared with other structures. Both quantitative and qualitative types of flaw formation are discussed in relation to plastic flow phenomena in vitreous networks.
\end{abstract}

\section{INT RODUCTION}

Fracture processes in many crystalline solids have, to a considerable degree, been elucidated by findings which indicate a close relationship between microcrack formation and dislocation interactions. In the case of vitreous solids, however, fundamental knowledge concerning the mechanisms of bond rupture has essentially been limited to statistical treatments of breakage data. Questions, for example, such as what internal energy changes may occur in a vitreous structure preceding fracture or relationships between breakage values and defect characteristics remain to be answered. It appears that glass under load does not react as the simple "brittle solid" as it has been described. In fact, A. H. Cottrell ${ }^{(1)}$ has emphasized the possible roll of plastic deformation in glass fracture. It is a well established fact that various types of glasses disclose marked differences in their mean fracture strength, and such variations need explaining if we are to more completely understand the vitreous solid state.

The purpose of the research described here was to quantitatively examine localized surface flaw formation in various glass networks and compare parameters of flaw length and number with the mean fracture values for the same systems. A chemical etching method(2) was utilized to display the linear flaws or surface defects. A value of the mean breaking strength was determined by using a concentrated force applied to fresh cleavage surfaces.

The linear surface defects in glass have been found to have properties which are related to internal structural variations and appear to be unique with this type of solid. In terms of morphology, movement under applied stress and energy characteristics, the linear flaws are somewhat analogous to dislocations. (3) From studies of the various surface flaw interactions came the ultimate question concerning their involvement in the bond rupture process and in this paper are data pertinent to this problem.

Based on their unique properties of movement under applied stress, it is suggested that the linear flaws are one means by which plastic deformation occurs in noncrystalline solids. As localized forces are applied, a part of the mechanical stress is released by surface flaw formation which creates a region of plastic deformation. Within this deformed region the flaw density may become sufficiently high to produce a microcrack, the

"The University of Michigan,Willow Run Laboratories, Institute of Science and Technology, Ann Arbor, Michigan. 
precursor of ultimate fracture. Calculations are presented for the surface energy of flaw formation and the value obtained is discussed in relation to a proposed mechanism of fracture. These hypothetical considerations are compared with the experimental data.

That these surface defects are intimately related to the breakage process, has been shown in a systematic investigation of the extension and interaction of both linear and loop type flaws under different conditions of mechanical stress. (4) These studies were, however, carried out with one type of glass structure. The specific characteristics of the linear flaws such as length and number are not only influenced by external forces but, as shown by ionic substitutions, ${ }^{(5)}$ are composition sensitive. Data are presented here which demonstrate that in addition to composition variations, a change in basic structure of the same material may also produce quantitative variations in the linear flaw formation. The mean value of flaw length and number was determined in fused and crystalline silica. It is shown that in crystalline silica the flaw build up with applied stress is of a somewhat different nature than observed in fused silica. Variations in flaw build up in the se brittle systems are discussed in relation to their fracture strengths.

\section{SURFACE ENERGY AND FLAW FORMATION}

In this section the energy involved in the actual formation of the linear flaws will be discussed. Although the methods used in the calculations only provide approximate values, the order of magnitudes may be compared with the surface energy involved in the formation of macroscopic fracture surfaces. Also, by way of recapitulation, the following statements summarize the present evidence for and against the flaws being other than fine cracks which are beyond the resolution of the ordinary microscope. In addition, this summary serves as a listing of factors to be considered in the experimental portions of the paper.

1. From previous experimental observations the linear flaws on glass are very localized surface displacements (approximately 12 microns deep) initiated by mechanical or thermal stresses. Flaw formation is dependent on the manner in which the stress fields are applied. Fine cracks would also form in accord with the stress field but would be expected to extend deeper than 12 microns.

2. A region of stress exists around each flaw line, thus accounting for a more rapid chemical attack and specific etch features. Fine cracks even beyond the resolution of the microscope do not etch in the same manner as the flaws.

3. The flaw lines may move under an applied stress. At a minimum length of around 50 microns the flaw lines collapse into rows of etch pits. (2) Fine cracks once formed do not move or completely collapse under stress.

4. The linear flaws are unique in the sense that they form "mirror image" patterns on the matching surfaces of reopened macro-fissures. ${ }^{(3)}$ The flaws are displayed as fine etch grooves on both matching surfaces, indicating they formed independently but are similar in outline because of exposure to identical stress conditions. Fine line cracks are not produced on the surfaces of internal fissures.

5. A periodic wave pattern of linear flaws was associated with the kinetics of an applied shearing force.(3) Fine cracks are not arranged in such an intricate pattern.

The methods of producing linear flaws using a controlled localized stress 
applied to fresh surfaces have been described in detail.(2) The length of flaws $F_{\ell}$ created by a dynamic indenter is taken as a measure of the bond strength and the flaw number (per millimeter of trace line) $F_{n}$ an indication of the rigidity of the network. The product of these two parameters is an indication of the overall response of the system to applied stress and is designated by

$$
\left(\mathrm{F}_{\ell}\right)\left(\mathrm{F}_{\mathrm{n}}\right)=\mathrm{N}_{\mathrm{b}}
$$

where $\mathrm{N}_{\mathrm{b}}$ is a relative measure of the number of bonds disrupted.

The relationship between stress, $\sigma$, at a radial distance $r$ from the point of loading on an indenter is given by

$$
\sigma=\left[\frac{(1-2 \nu)}{2 \pi}\right] \mathrm{P} / \mathrm{r}^{2}
$$

where $P$ is the applied load force and $\nu$ is Poisson's ratio. A terminal stress $\sigma_{t}$ occurs at the end of a flaw initiated at the trace line and is found by substituting $\mathrm{F}_{\ell}$ for $\mathrm{r}$ in equation 2 .

$$
\sigma_{\mathrm{t}}=\mathrm{KP} / \mathrm{F}^{2}
$$

where $\mathrm{K}$ is a constant involving Poisson's ratio $\nu$ as,

$$
\mathrm{K}=\left(\begin{array}{lll}
1-2 & \nu
\end{array}\right) / 2 \pi
$$

In various experimental studies, it has been shown that the load $\mathbf{P}$ determines the extent of radial flaw formation, before the terminal stress $\sigma_{t}$ has been attenuated to a level where it is exactly counterbalanced by cohesive energy. The relationships between these various parameters and the physical application of the indenter are shown diagramatically in Fig. 1.

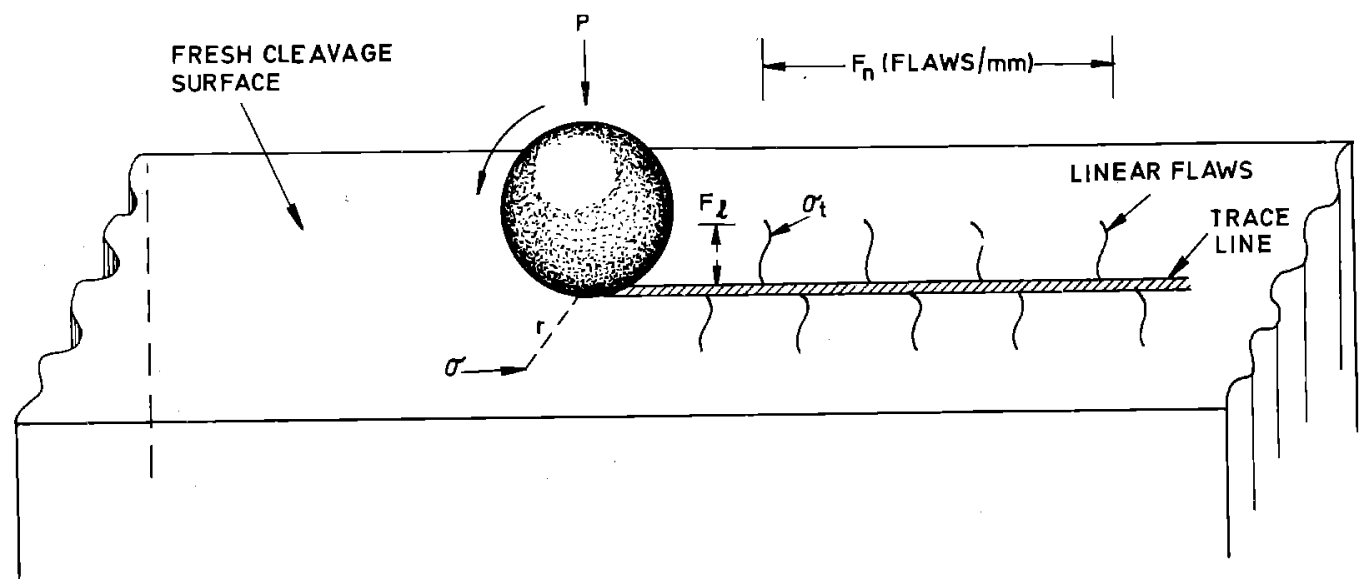

Fig. 1. Diagramatic representation of flaw parameters in relation to the dynamic loading device.

If a stress $\sigma_{\mathrm{I}}$ is applied normal to a surface (such as used here) the length $\mathrm{C}$ of a flaw or "microcrack" has been given by Cottrell(6) as,

$$
\mathrm{C}=\frac{2 \mathrm{G} \gamma^{\prime}}{\pi(1-\nu) \sigma_{n}^{2}}
$$

and in terms of the applied stress

$$
\sigma_{n}=\left(\frac{2 G \gamma^{\prime}}{\pi(1-\nu) C}\right)^{\frac{1}{2}}
$$


where $G$ is the shear modulus (for glass $2.8 \times 10^{11}$ dynes $/ \mathrm{cm}^{2}$ ), $\nu$ is Poisson's ratio ( $1 / 3$ for glass) and $\gamma^{\prime}$ is the "effective surface energy." This effective surface energy represents the energy involved in the flaw formation and not the true surface energy of the material. Since $C$ and $\mathrm{F}_{\ell}$ are two different symbols for flaw length, the Cottrell stress in equation 6 and the terminal stress in equation 3 can be combined to give $\gamma^{\prime}$ in terms of known and measured parameters:

$$
\gamma^{\prime}=\frac{\pi(1-\nu) \mathrm{K}^{2} \mathrm{P}^{2}}{2\left(\mathrm{~F}_{\ell}\right)^{3} \mathrm{G}}
$$

Using a load $P=500$ grams on the indenter produces flaws whose average length $F_{\ell}$ is around $0.07 \mathrm{~cm}$. After inserting these values in equation 7 the effective surface energy of flaw formation is found to be

$$
\gamma^{\prime} \simeq 11.4 \mathrm{ergs} / \mathrm{cm}^{2}
$$

This value is approximately one-thirtieth the reported value for the surface energy involved in the creation of a fresh surface (approx. $300 \mathrm{ergs} / \mathrm{cm}^{2}$ ). The effective surface. . rgy involved in flaw formation is, therefore, considerably less than th surface energy necessary to produce separation or cleavage of the structure.

It is interesting to note that the value of the flaw surface energy obtained by equating the Orowan( ${ }^{(7)}$ relation,

$$
\sigma=\left(\frac{\gamma^{\prime} \mathrm{E}}{2 \mathrm{C}^{\top}}\right)^{\frac{1}{2}}
$$

with equation 3 , is of the same order of magnitude $\left(\gamma \simeq 8.4 \mathrm{erg} / \mathrm{cm}^{2}\right)$ as given in equation 8. Equation 9 gives the value of the applied mean stress at which the "microscopic stress". at a flaw of atomic dimensions reaches the value of the molecular cohesion of the material. The flaw length $C^{\prime}$ in equation 9 is generally considered to be very small ( 1 to $2 \mu$ ); however, there has been speculation among various workers(6) as to the actual dimensions of these flaws in a vitreous network. Even though the length $\mathrm{F}_{\ell}$ of the chemically decorated flaws observed on glass are considerably greater than this assumed range, they do fit the requirements of minute dimensions of width and depth. For example, it has been consistently shown that flaws in glass are not the same as macroscopic cracks and do not etch in the same manner as ordinary cracks, even cracks just at the limit of visibility. The experimental evidence indicates that the flaws are less than 200-300A wide, perhaps less than $1 / 10$ the width of a crack which is just at the visible limit, with the depth of the flaws being around 12 microns. (2) Since these flaws fit the Orowan-Griffith criteria of minute dimensions it does not seem unreasonable to replace $C^{\prime}$ with $F_{\ell}$ in equation 9.

If it is assumed that the effective surface energy given in equation 8 is an approximation of the actual energy of flaw formation, then one may speculate as to the involvement of the flaws in the fracture process. Since the surface energy of flaw formation is considerably less than the energy of crack development, a portion of the applied mechanical force may be utilized in the energy of flaw formation, thereby locally relieving the mechanically or thermally applied stress and by this mechanism delay the formation of the macroscopic fissure. That a continual increase in applied stress will cause a local buildup of flaws in the load zone has been shown experimentally. (4) The flaws may, during this buildup, combine to form a microcrack (crack just at the limit of visibility) leading to the final rupture of the material. It has been demonstrated that when the flaw number reaches a value of around 100 per $\mathrm{cm}^{2}$ on a fresh surface (loaded with a concentrated force) a visible crack is produced. Assuming an incremental increase of approximately $11 \mathrm{ergs} / \mathrm{cm}^{2}$ in effective surface energy for each 
flaw contributing to the final microcrack, it may be seen from equation 8 that it is only necessary to combine around 30 flaws to locally increase the surface energy to the point of crack formation. Although it has been shown that flaw buildup precedes crack formation, the actual mechanism by which the linear flaws combine to form a microcrack is not precisely understood. Since, however, the linear flaw characteristics are different in different systems, the values of breaking strengths would be expected to be related to the flaw parameters if this concept of linear flaw involvement in fracture processes is reasonable.

A critical test for the validity of this hypothesis of incremental effective surface energy increase was made by comparing the experimentally determined values of breaking strength with the flaw parameters in various types of glasses. Previous studies have indicated that certain criteria must be followed if such a comparison is to be made. For example, the measurements were made on fresh breakage surfaces to eliminate the problems of surface energy variations by contamination. Since the flaw buildup phenomenon is a very localized effect, the strength measurements were conducted by employing concentrated breaking forces.

\section{EXPERIMENTAL}

In general the method of determining the breaking strength of fresh surfaces by concentrated forces was similar to that employed by Argon, Hori, and Orowan. (8) A 1/8" diameter steel ball was pressed into the fresh surface until breakage occurred. The ball was mounted on a Tinius Olsen tensile strength tester. The force was applied normal to the fresh breakage surfaces using a loading rate of 60 pounds per minute. The breakage results are expressed as the recorded load -- $L_{B}--$ (in pounds) necessary to produce a visible Hertz cone fracture (generally a faintly audible "click" could be heard when the visible crack formed). The breakage surfaces were about $3 / 8^{\prime \prime}$ wide and $1^{\prime \prime}$ to $2^{\prime \prime}$ long. The samples were scored with a regular glass cutter and the breaking force was controlled to produce a smooth test surface. The strength determinations on each given sample were completed less than five minutes after exposing to air. It has been shown (4) that the change in flaw characteristics is not pronounced (less than $1 \%$ change) during the first few minutes of exposure to the atmosphere. At least 50 strength determinations were made on each type of glass; the standard deviation of each test group was between 40-50\% of the mean value.

Samples of the same composition were used for the determination of the flaw parameters. Unless specified otherwise, a nomimal load (P) of 500 $g$ was used on the dynamic indenter. (2) Over 50 flaws were measured on each glass used in the analysis. When examining hard, brittle structures such as silica and pyrex glass, the steel ball on the dynamic indenter was replaced with a carbide cutting wheel. The cutting wheel produced higher stresses at the trace line (the load $\mathrm{P}$ on the indenter was still below the limit to produce visible cracks) and initiated flaws which could not be accomplished with the wider trace line produced by the $5 / 16^{\prime \prime}$ rolling ball.

\section{RESULTS}

Both commercial and synthetic glasses were used in this study. Glasses were chosen which were known to have markedly different flaw parameters.

\section{A. Commercial Glasses}

The type of glass, flaw parameters, mean cracking load, and number 
of break tests are listed in Table I. The result of plotting the mean break-

TABLE I

Indentation Strengths and Flaw Parameters in Commercial Glasses

\begin{tabular}{|c|c|c|c|c|c|}
\hline Type of Glass" & $\begin{array}{l}\text { Number } \\
\text { of Tests }\end{array}$ & $\begin{array}{l}\text { Cracking Load } \\
\mathrm{L}_{\mathrm{B}}-1 \text { bs.(av.) }\end{array}$ & $F_{\ell}$ & $\mathrm{F}_{\mathrm{n}}$ & $\mathrm{N}_{\mathrm{b}}$ \\
\hline Sheet Glass & 73 & 268.7 & \multicolumn{2}{|c|}{$1.564 \mathrm{~mm} 0.48$} & 0.751 \\
\hline Plate Glass & 79 & 210.2 & 0.335 & 1.61 & 0.539 \\
\hline Clear Flint-A & 66 & 152.1 & 1.144 & 0.38 & 0.435 \\
\hline Clear Flint $-B$ & 75 & 130.7 & 0.255 & 1.35 & 0.345 \\
\hline
\end{tabular}

- $A$ and $B$ indicate different sample sources.

ing load against $\mathrm{N}_{\mathrm{b}}$ is shown in Fig. 2, and it may be seen that there is a direct relation between mean strength and the parameter expressing the

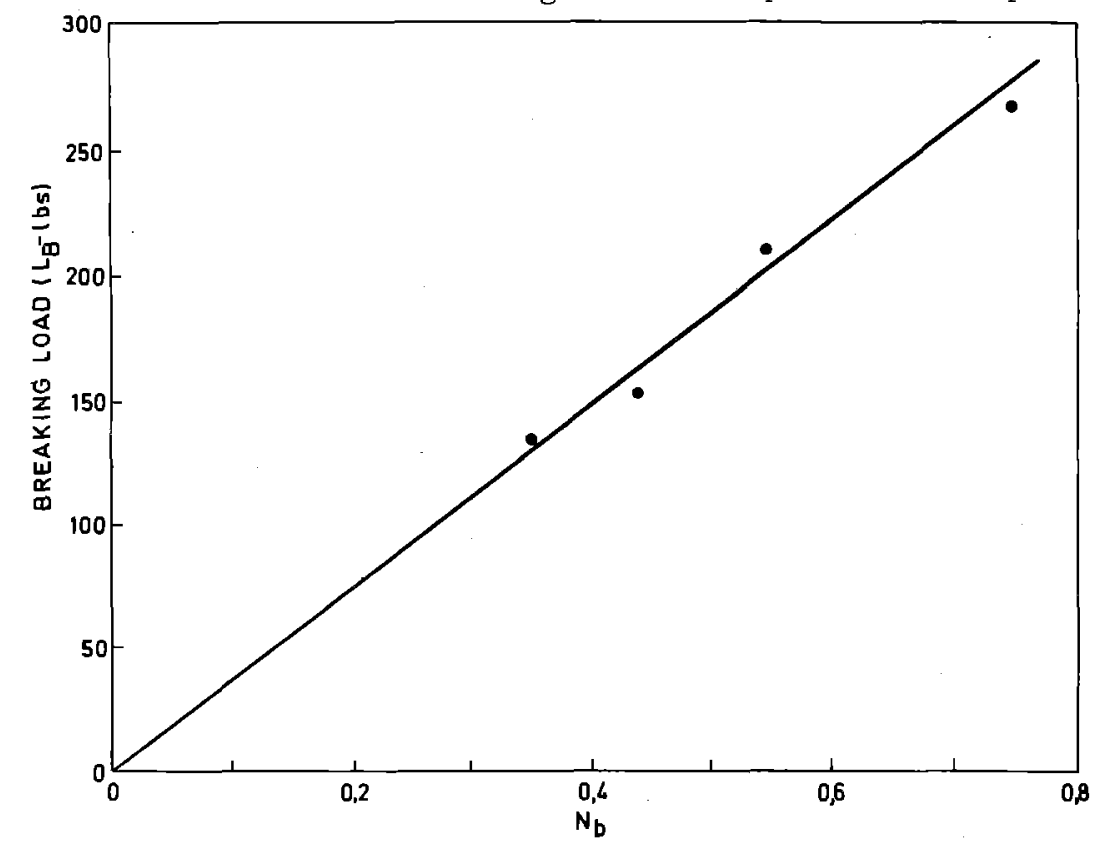

Fig. 2. Variation of indenter strength with linear flaw formation in commercial glasses.

overall bond readjustment in the flaw formation. Even though there are marked differences in the $F_{\ell}$ and $F_{n}$ values in this series, it appears that $\mathrm{N}_{\mathrm{b}}$ expresses the capability of a given structure to readjust to the applied stress. It is only this "final" effect which becomes important in relating the flaw formation to the breaking strength. From these data it appears that the localized stresses may be relieved by having a structure which exhibits a few long, or one with numerous short flaws. Whenever the $N_{b}$ values are comparable, the mean strengths will be similar.

This concept of total effective flaw formation may not, however, be extended to systems markedly different in composition such as the one discussed in the next section. It is significant that the curve in Fig. 2 extrapolates to zero strength at zero $\mathrm{N}_{\mathrm{b}}$. The zero extrapolation in Fig. 2 indicates that if we have a hypothetical glass with zero $\mathrm{N}_{\mathrm{b}}$ the structure would be completely brittle or rigid and could not locally relieve stress by flaw formation. Such a structure would, therefore, not support a localized force without fracture. 


\section{B. Synthetic Glasses}

In Table II are listed the flaw parameters and average breakage values for a series of three component glasses with varying silica content and a constant soda-lime ratio $\left(\mathrm{Na}_{2} \mathrm{O} / \mathrm{CaO}=1.14\right.$ on wt. $\%$ basis $)$. Also given in

\section{TABLE II}

Indentation Strengths and Flaw Parameters in Experimental Glasses (soda-lime ratio is 1,14 )

\begin{tabular}{|c|c|c|c|c|c|}
\hline \multirow[b]{2}{*}{$\mathrm{SiO}_{2}$} & \multirow{2}{*}{$\begin{array}{l}\text { Number of } \\
\text { Break Tests }\end{array}$} & \multirow{2}{*}{$\begin{array}{l}\text { Cracking Load } \\
\text { LB }_{\text {-1bs. (av) }}\end{array}$} & \multicolumn{3}{|c|}{ Flaw Parameters } \\
\hline & & & $\mathrm{F}_{\ell}$ & $F_{n}$ & $\mathrm{~N}_{\mathrm{b}}$ \\
\hline $100 \%$ (fused silica) & 50 & 25.9 & 0.0160 & $\operatorname{mm} 7.71$ & 0.123 \\
\hline $70 \%$ & 51 & 99.8 & 0.909 & 0.76 & 0.691 \\
\hline $65 \%$ & 55 & 156.9 & 0.592 & 1.69 & 1.000 \\
\hline $60 \%$ & 58 & 119.5 & 0.166 & 5.13 & 0.852 \\
\hline
\end{tabular}

Table II are the experimentally determined values of flaw parameters and mean breaking strength for fused silica. In Fig. 3 it may again be seen that there is a linear relation between $N_{b}$ and the breaking strength. The

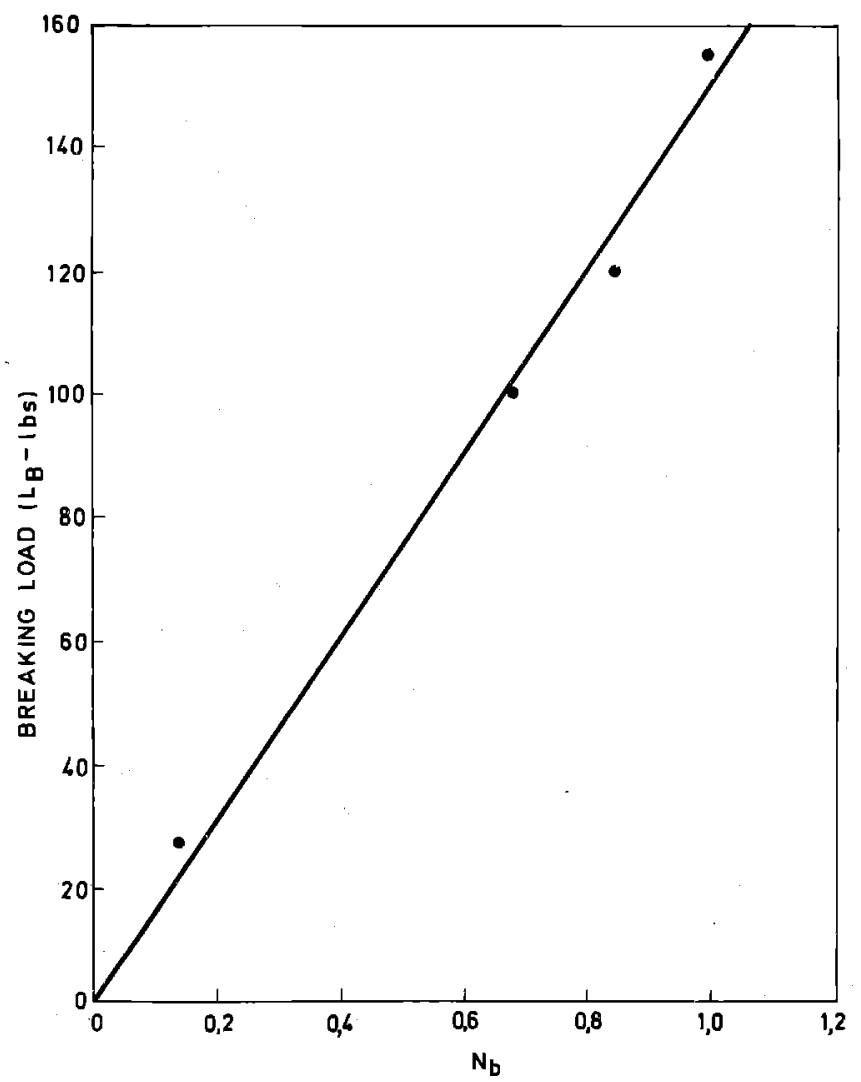

Fig. 3. Variation of indenter strength with linear flaw formation in synthetic glasses.

point for fused silica lies low on the curve and the significance of this will be covered in greater detail in the following section. This curve also appears to extrapolate to the zero coordinate point, and it should be noted that the change in $\mathrm{N}_{\mathrm{b}}$ with the mean breaking load (slope of the curve) is less pronounced than the results in Fig. 2 for the commercial glasses. The commercia]. systems demonstrate a greater localized flaw formation under a given loading force. 


\section{Response of Brittle Structure to Stress}

The fact that fused silica disclosed a very low strength and $\mathrm{N}_{\mathrm{b}}$ under the localized concentrated force indicates a brittle structure, although fused silica fibers are known to be very strong under uniform tensile forces, the situation is considerably different when the forces are localized and shear stresses are created. Under conditions of nonuniform loading the very rigid Si-O network does not yield and this results in gross or complete bond breakage at low applied stresses.

This brittle effect is also expressed in the flaw parameter data in Table II. The flaws are short (low $\left.F_{\ell}\right)$ indicating a high bond strength and very numerous (high $F_{n}$ ) indicating a brittle or rigid network. The overall bond readjustment $\left(\mathrm{N}_{\mathrm{b}}\right)$ is considerably lower than the values for the other glas ses. The flaw formation is not of sufficient linear extent to relieve the stresses by creating extensive defects of low surface energy, therefore, visible cracking occurs at a much lower value of applied force. Very short flaws build up rapidly at the shear region around the loading tool, whereas in the case of the less brittle glasses the flaws are less numerous but also extend outward a considerable distance from the load point and in a sense "distribute" the load over a larger area.

The very high strength of uniformly loaded silica fibers is also explained by this same concept of flaw formation. With an extension type of loading the forces are uniformly distributed over the surface of the material. The flaws, as shown in Table II, are very short and the probability for the buildup of, let us say, a group of 30 at high stresses is less than in glasses with longer flaw networks which may interact. In the nonuniform, localized type of loading, more extensive flaws or high $\mathrm{N}_{\mathrm{b}}$ contributes to a high strength and in the case of uniform loading conditions a low value of $\mathrm{N}_{\mathrm{b}}$ is conducive to high strength values.

\section{DEFECT FORMATION IN FUSED AND CRYSTALLINE SILICA}

The brittle nature of both vitreous and crystalline silica was also examined in a some what different manner. In equation 3 , the terminal stress is related to the critical stress $\sigma_{c}$ to produce flaws. This critical stress cannot, however, be obtained by directly substituting the $F_{\ell}$ values in equation 3 since this relationship assumes flaw formation to be a monotonic function of applied load ( $r=0$ at $P=0$ by extrapolation). Experimentally it is found that there is an apparent yielding of the glass structures at the low load region which alters the slope of the flaw length versus applied load curve.

The correct form of the load-flaw length relationship is derived by considering the dynamics of flaw formation. From equation 3 , the incremental extension of flaw lines with load is

$$
\frac{\mathrm{dF}_{\ell}}{\mathrm{dP}}=1 / 2\left(\frac{\mathrm{K}}{\sigma_{\mathrm{c}}}\right)^{\frac{1}{2}} \mathrm{p}^{-\frac{1}{2}}
$$

The mean flaw length may be equated with the force exerted on the test surface as

$$
\int \mathrm{dF}_{\ell}=\left(\frac{\mathrm{K}}{\sigma_{c}}\right)^{\frac{1}{2}} 1 / 2 \int \mathrm{p}^{-\frac{1}{2}} \mathrm{dp}
$$

After integration the relationship between flaw length and load is,

$$
F_{\ell}=\left(\frac{K}{\sigma_{c}}\right)^{\frac{1}{2}} p^{\frac{1}{3}}+b
$$


where $b$ is a constant and physically is related to the length of flaw created by a threshold stress which must be introduced into, a given network to initiate flaws. Experimental confirmation of equation 12 has been shown (5) and this relationship will be subsequently utilized in the analysis of the brittle systems. From equation 12 and the empirical relations, $\sigma_{c}$ is given by

$$
\sigma_{c}=\mathrm{K} / \mathrm{a}^{2}
$$

where $a$ is the slope determined from the $F_{\ell}$ vs $p^{\frac{1}{2}}$ curve.

The results of applying the indenter to fused silica and a quartz crystal are shown in Fig. 4. Each point is the average of over 50 measurements

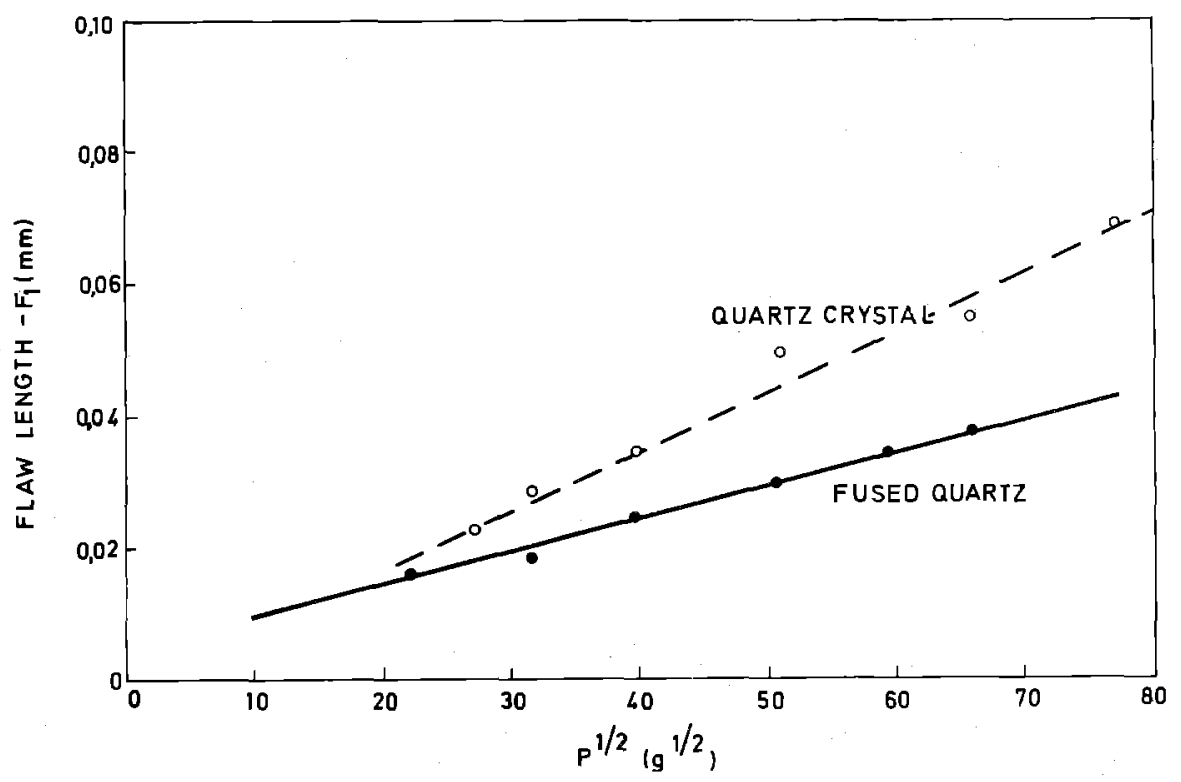

Fig.4. Elaw formation in crystalline and fused quartz using controlled loading forces.

of flaw length. It is immediately apparent from these data that the quartz crystal disclosed greater flaw formation than the silica glass. It is also noticed that the constant $b$ is negative in the case of the crystal. In glass systems $b$ is generally found to be positive, indicating that a finite force must be applied to initiate flaw formation. One explanation for the negative value of $\mathrm{b}$ for the quartz curve in Fig. 4 is the possibility that during the initial loading a localized yield or slip occurs along the crystalline planes (region of easy glide). This initial yield only temporarily relieves the stress; with increasing load the localized defects appear, and the stress is now relieved through the surface energy of flaw formation. This hypothesis will be investigated in future experimentation.

The stress response effects as determined by the $F_{\ell}-P^{\frac{1}{2}}$ curves may also be compared by listing the constants in Equation 12 with $\sigma_{c}$ representing the critical stress of flaw formation and $b$ being a relative measure of flaw extension under the initially applied load. These values are listed in Table III for the experimental curves shown in Fig. 4 along with measurements on pyrex and a soda-lime-silica glass. The marked differences in the responses of these structures to applied stress is apparent. For example, the slope constant (a) shows a greater ordered, long range yield in crystalline quartz compared with fused structure, whereas both forms of silica demonstrate a much lower degree of flaw formation than in pyrex 
TABLE III

Emperical Constants and Gritical Stresses for Flaw Formations in Different Structures

\begin{tabular}{|c|c|c|c|}
\hline Material & $\sigma_{c}-p s i$ & $\mathrm{a}\left(\mathrm{m} \mathrm{m} / \mathrm{gm}^{\frac{1}{2}}\right)$ & $\mathrm{k}$ \\
\hline Quartz-crystal & 97,800 & $8.86 \times 10^{-4}$ & $-0,0008$ \\
\hline Quartz -fused & 320,000 & $4.90 \times 10^{-4}$ & +0.0047 \\
\hline Pyrex Glass & 29,200 & $16.25 \times 10^{-4}$ & +0.0462 \\
\hline $\begin{array}{l}\text { Soda-lime-silica } \\
\text { glass }\end{array}$ & 276 & $166.60 \times 10^{-4}$ & +0.8100 \\
\hline
\end{tabular}

or sheet glass. In terms of flaw formation, pyrex glass appears to be intermediate in structure between fused silica and soda-lime-silica glasses. From its brittle nature one would expect pyrex to have a lower indenter strength than soda-Iime glasses and indeed Argon, Hori, and Orowan(8) found this to be the case. The slope constants are also in agreement with the breaking strength data. The calculated values of $\sigma_{c}$ disclose a much higher critical stress for flaw formation in the $\mathrm{SiO}_{2}$ structures as compared with pyrex and sheet glass.

\section{FLAW FORIMATION AND PLASTIC FLOW}

The demonstration of a direct relationship between flaw formation and the breaking strength of various glasses provides quantitative evidence for the important role that these surface flaws play in bond rupture. Flaw growth relieves stress in localized regions through the release of effective surface energy. The surface energy of an individual flaw amounts to about one-thirtieth the energy utilized in the creation of new surfaces in bond rupture. Because of their low energy the surface flaws form at critical stresses considerably below those necessary to produce fracture. In regions of locally applied forces, networks of these flaws are formed and with increasing stress may combine to form a microcrack with subsequent failure of the network.

Because of the ease of formation (at moderate stresses) and low effective surface energy, it is not difficult to conceive of these surface flaws being involved in plastic flow mechanisms. Independent evidence for localized plastic flow in glass is offered by D. M. Marsh(9) from experiments and a comprehensive analysis of Vickers diamond hardness tests. This author points out that brittle fracture theories are "grossly inadequate" to explain the strength behavior of glasses. Evidence of plastic flow is utilized to account for the deficiency in the brittle fracture theories. The physical nature of the Vickers test is such that the possible involvement of surface defect formation is not taken into consideration. The deformation process is considered as a uniform radial bulk flow around the point of load application.

A process of localized plastic flow may also be accounted for, at least partially, by surface flaw formation. The results in the preceding sections demonstrate that when flaw formation is extensive (large $F_{\ell}$ ) the breaking foree is high. The plastic flow or slip process is not a uniform radial flow around the load region, but instead takes place along certain linear arrays in the network. The radial extent of these linear flaws or planes of flow is determined by such factors as applied stress, surface energy, as well as the type of structure or composition, as demonstrated in Figs. 2 and 3.

Variations in the network conformities of glasses may have very pronounced effects on the flaw formation, as shown in a recent study of ionic substitutions.(5) A spontaneous initiation of a pattern of flaws has also been 


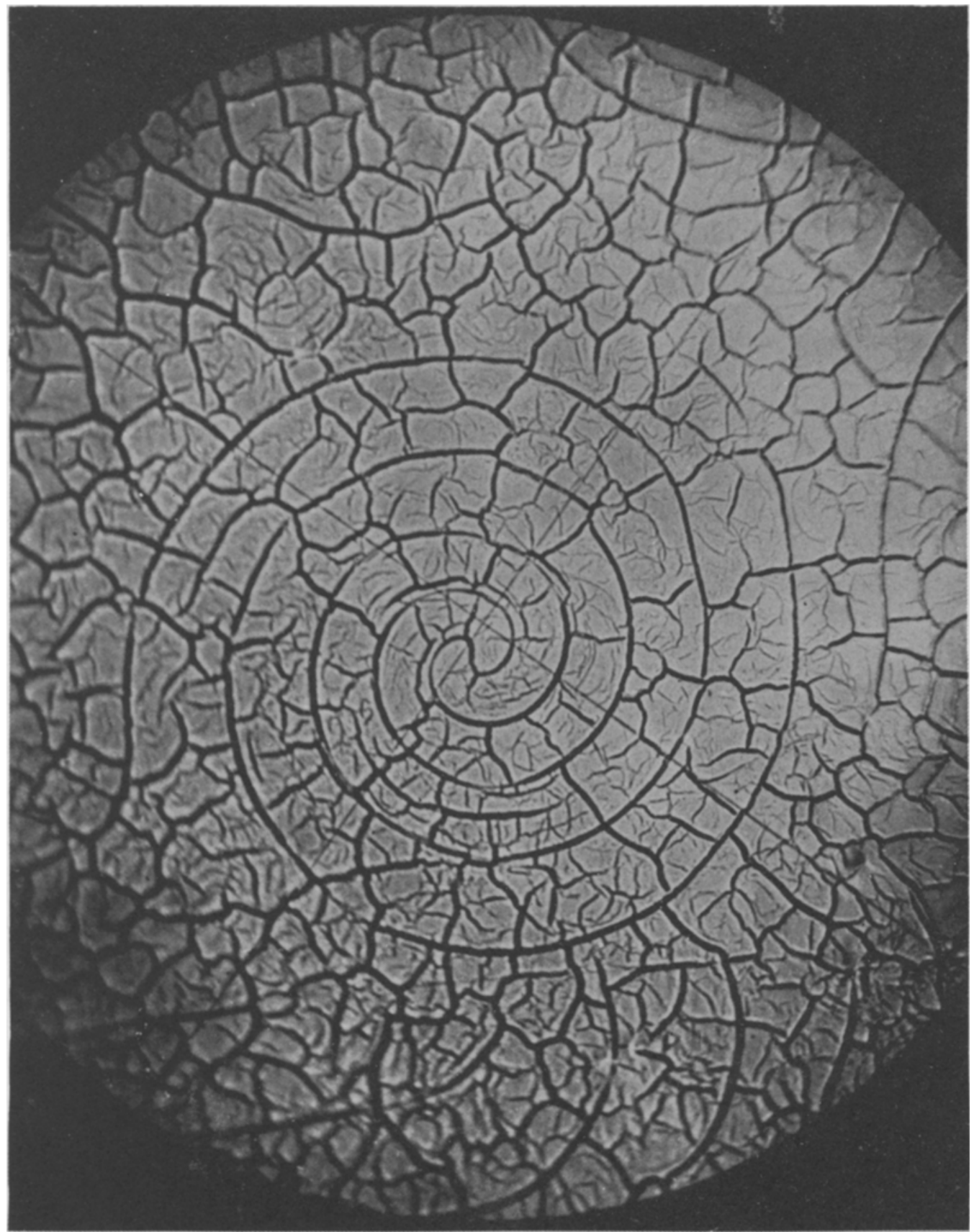

Fig.5. Spiral pattern believed to represent a spontaneous, localized plastic deformation (105X). 
observed to take place in limited composition regions with the formation of interesting spiral shapes. (2) Studies of the flaw parameters indicate that this spiral pattern forms in a brittle or rigid type of network containing regions with a high degree of order (near the point of crystallization). Specific groupings form localized regions of torque stress in the glass and when one of these regions is located near or on a fracture plane, it is proposed that plastic flow occurs through flaw formations which follow the torque stress field. An example of this type of suggested "spontaneous" plastic flow is shown in Fig. 5 within a simple soda-lime-silica system. This same type of pattern has also been artificially produced by applying a "micro-spade" to a fresh cleavage surface and creating a torque stress.

This mechanical duplication of the spontaneous spiral patterns clearly demonstrates the release or partial release of a torque stress through the linear flaw formation.

There are other qualitative effects which strongly suggest a plastic flow mechanism through flaw formation. One such case is produced when parallel steel needle or diamond traces are produced on fresh cleavage surfaces of soda-lime glasses. (3) A cyclic flaw pattern is formed in the region between scratches separated by distances of approximately $0.2 \mathrm{~cm}$. The period of the cyclic flaw pattern is related to the velocity of the scratching tool and this strongly suggests a dynamic displacement or plastic flow effect.

From the preceding, it may be seen that both the quantitative and qualitative aspects of linear flaw formation suggest a mechanism by which vitreous structures may exhibit plastic flow. The plastic flow takes place in linear arrays at stresses considerably below the theoretical cohesive bond strength of the material.

Received October 29, 1965.

\section{REFERENCES}

1. A.H. Cottrell

2. W.C. Levengood

3. W.C.Levengood; T.S. Vong

4. W.C. Levengood

5. W.C. Levengood

6. B.L.Averbach; D.K. Felbeck; G.T.Hahn; D.A.Thomas, eds.

7. E. Orowan

8. A,S.AIgon; Y.Hori; E. Orowan

9. D.M.Marsh

10. W.C. Levengood; T.S. Vong
Proc.Roy.Soc., 276A, 1 (1963;

J. A ppl. Phys., 32, 2525 (1961) .

J.Chem.Phys., 31, 1104 (1959).

J. Appl. Phys. . 35, 424 (1964).

J. Phys, Chem. Solids, 24, 1011 (1963).

Fracture, John Wiley and Sons, Inc., New York, (1959).

Z. Krista llogr. (A), 89, 327 (1934).

J. Am.Ceram. Soc., 4ㄴ, 86 (1960).

Proc.Roy.Soc., London 279, 420 (1964).

J. A ppl. Phys. , 31, 1416 (1960). 
RÉSUMÉ - Une comparaison expérimentale a été établie entre la force de rupture de surfaces de clivage fraiches sur différents verres et les paramètres de défaut superficiels. Une relation directe a été trouvée entre le produit $\mathrm{N}_{\mathrm{b}}$ de la longueur et du nombre de défauts et la pression moyenne nécessaire à la production de la rupture dans des surfaces localisées. Cette relation est attribuée à l'énergie superficielle utilisée pour la crêation du défaut. On avance une théorie selon laquelle une force localisée provoque le prélèvement d'une partie de la contrainte mécanique par énergie de défaut superficiel, produisant une région confinée de déformation plastique. On a observé que la formation de défauts dans la silice fondue est moins étendue, et en conséquence, que sa structure supporte des forces moins localisées avant la fracture que les verres coinmerciaux. La structure du quartz fondu est modifiée par addition d'oxyde de sodium et d'oxyde de calcium; ces verres à trois composants présentent également la relation directe entre $\mathrm{N}_{\mathrm{b}}$ et la force de rupture. La formation quantitative de défauts, obtenus par un appareil à entailler dynamique, dans des systèmes tels que le quartz fondu et cristallin sont comparés à d'autres structures. On discute les formations de défauts à la fois quantitatives et qualitatives en relation avec les phénomènes d'écoulement plastique dans les systèmes vitreux.

ZUSAMMENFASSUNG - Ein experimenteller Vergleich wurde gemacht zwischen der Bruchfestigkeit von frischen Spaltflächen auf verschiedenen Glassorten und den Parametern von Oberflächensprüngen.

Ein direkter Zusammenhang zwischen dem Produkt Nb von Sprunglänge und -anzahl und dem mittleren Druckwert zur E⿰zielung eines lokalen Bruches wurde gefunden. Dieser Zusammenhang wird auf die zur Sprungerzeugung verbrauchte Oberflächenenergie zurückgeführt. Eine Theorie wird entwickelt, nach der bei einer lokal aufgebrachten Belastung die mechanische Spannung örtlich zum Teil durch die Sprungoberflächenenergie vermindert und ein begrenztes Gebiet plastisch verformt wird.

In geschmolzenem Kiesel wurde eine weniger ausgebreitete Sprungbildung beobachtet und der Widerstand des Materials gegen eine örtliche Kraft war infolgedessen geringer als der von kommerziellen Gläsern vor dem Bruche. Die Zusammensetzung des Schmelzquarzes wurde durch Hinzufügen von Soda und Kalziumoxyd verändert. Diese Drei-Komponenten-Gläser zeigten auch den direkten Zusammenhang zwischen $\mathrm{N}_{b}$ und der Bruchkraft. Unter Verwendung einer dynamischen Kerbmaschine wurde die quantitative Sprungbildung in geschmolzenem und kristallinem Quarz mit anderen Materialien verglichen. Quantitative und qualitative Arten von Sprungbildungen werden im Zusammenhang mit plastischen Fliesserscheinungen in Glasgefügen besprochen. 